\section{Translation of research}

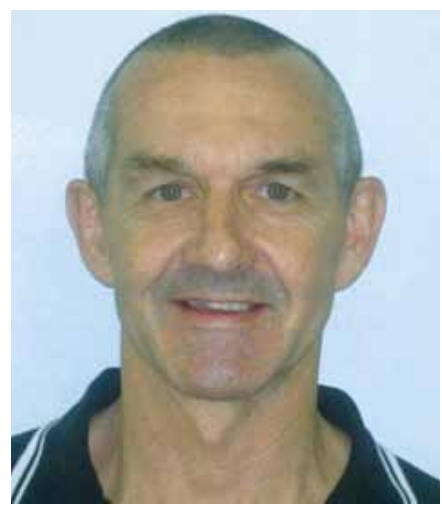

Sports medicine and exercise science has blossomed as a discipline. For example, in the 1960s the understanding of fatigue was restricted to changes in substrates and metabolites that could be measured in a muscle biopsy. The explanation of fatigue revolved around these measurements and interventions were planned using this limited knowledge. Now, over 40 years later, the functioning of the brain and muscles can be measured simultaneously during a bout of exercise and therefore the understanding of fatigue has both broadened and deepened. It goes without saying that the interventions have become more enriched with a much stronger impact. There are many other examples showing that the knowledge database has increased exponentially as the discipline has evolved. However, just like other branches of science, the gap between the knowledge of a topic and the translation of this knowledge into action is still wide.

In South Africa two sports are setting the trend in translating research into action. Firstly, the South African Rugby Union has established a medical and scientific committee that has the mandate to incorporate principles of best practice into player management. The goal is to ensure that the game is made safer for the players - the BokSmart programme (www.boksmart.com) is aligned to this goal and implements training courses around the country. Indeed, over 20000 coaches and referees have been trained since the programme began in 2008. Also about 50 evidence-based papers, on a range of topics from nutrition for rugby, to return-to-play after injury, are available on their website.

The second example is cricket. Although they are a few years behind rugby in terms of developing their medical and scientific infrastructure, a full-time research officer has recently been appointed by Cricket SA to co-ordinate and stimulate research around the country. The goal is to foster communication between the coaches, players and researchers to ensure that relevant questions are answered and any intervention programmes, as a result of this research, are implemented in a systematic way. Both these sports have the infrastructure now to translate research in action - the results of which will most certainly be noticed from a performance perspective, and also from a player welfare perspective. The bar has been raised; other sports need to establish their own similar structures which encourage multi-disciplinary collaboration and the capacity to translate research into action.

The same concerns exist in the health and wellness field. Although much is known about the value of exercise and the risk of physical inactivity, countries all over the world are faced with similar challenges of making their inhabitants more physically active. This is not a medically or scientifically based problem. This is based on the fact that more information about the value of exercise-induced adaptations is not going to be the deal-breaker or catalyst that encourages people to lead more physically active lives. Although certain medical insurance companies are setting the trend and providing rewards and incentives for their members who can demonstrate their adherence to a physically active lifestyle, the problem requires holistic input from a variety of sources. For example, town planners need to plan suburbs to make it easier and safer for people to cycle to work. They need to provide more parks for leisure time activities. Schools need to join in and create opportunities and facilities for their pupils to engage in exercise. Businesses need to provide facilities that make it easier for their staff to exercise during breaks, and then reward employees who remain physically active. Providing everyone shares a common goal this next step should not be too difficult to implement.

This edition of the journal has a range of topics which fit somewhere on the continuum between basic research and implementation. For example, there are two studies on injuries in cricket players, and a study on trail runners. There is a commentary on physical activity as a risk factor for non-communicable disease, a commentary on cerebral damage in diving and an excellent article on fatigue that was previously published in the British Journal of Sports Medicine. I'm sure the papers will provoke ideas of ways in which the outcomes of the papers can be implemented.

The format of the journal is changing slightly to align it with the requirements for the PubMed database. This is the first step in the process of having the contents published, which we anticipate will happen sooner rather than later.

Mike Lambert

Editor-in-Chief 